\title{
Transcranial direct current stimulation as a motor neurorehabilitation tool: an empirical review
}

\author{
Ana Sánchez-Kuhn ${ }^{1}$, Cristian Pérez-Fernández ${ }^{1}$, Rosa Cánovas² ${ }^{2}$ Pilar Flores ${ }^{1,2}$ and Fernando Sánchez-Santed ${ }^{1,2^{*}}$
}

From 4th International Work-Conference on Bioinformatics and Biomedical Engineering-IWBBIO 2016 Grenada, Spain. 20-22 April 2016

${ }^{*}$ Correspondence:
fsanchez@ual.es
${ }^{2}$ Instituto de
Neurorehabilitación Infantil
InPaula, Almería, Spain
Full list of author information
is available at the end of the
article

\begin{abstract}
The present review collects the most relevant empirical evidence available in the literature until date regarding the effects of transcranial direct current stimulation (tDCS) on the human motor function. tDCS in a non-invasive neurostimulation technique that delivers a weak current through the brain scalp altering the cortical excitability on the target brain area. The electrical current modulates the resting membrane potential of a variety of neuronal population (as pyramidal and gabaergic neurons); raising or dropping the firing rate up or down, depending on the nature of the electrode and the applied intensity. These local changes additionally have shown long-lasting effects, evidenced by its promotion of the brain-derived neurotrophic factor. Due to its easy and safe application and its neuromodulatory effects, tDCS has attracted a big attention in the motor neurorehabilitation field among the last years. Therefore, the present manuscript updates the knowledge available about the main concept of tDCS, its practical use, safety considerations, and its underlying mechanisms of action. Moreover, we will focus on the empirical data obtained by studies regarding the application of tDCS on the motor function of healthy and clinical population, comprising motor deficiencies of a variety of pathologies as Parkinson's disease, stroke, multiple sclerosis and cerebral palsy, among others. Finally, we will discuss the main current issues and future directions of tDCS as a motor neurorehabilitation tool.
\end{abstract}

\section{Background}

The central nervous system (CNS) works thanks to the communication between more than 100,000 millions of neurons, whose activity and networking is modulated by chemical and electrical processes [1]. Across history, humans have been trying to alter the electrical brain processes to enhance human's brain function, for the treatment of psychopathologies and for a better understanding of the brain physiology. For example, in the antiquity, modulation of the electrical processes of the brain started with the use of electrical impulses of torpedo fishes applied directly on the CNS, for therapeutic purposes [2]. In 1746, Musschenbroek (1692-1761) used Leyde jars and electrostatic devices to treat neuralgia, contractures and paralysis. The discovery of biometallic 
electricity and the invention of the voltaic battery augmented the interest in the therapeutic effects of galvanism. Afterwards, Duchenne de Boulogne (1806-1875) upgraded the electrotherapy with volta and magnetofaradaic apparatuses. Fortunately, in the past Century, the technological advances and its integration in health sciences have let us go from uncontrolled and unsafe interventions with side effects to well-controlled, more effective and safe stimulation devices [3].

Currently, the most used stimulation devices can be divided into invasive techniques, such as deep brain stimulation (DBS), and non-invasive brain stimulation (NiBS) techniques, whose most representative methods are transcranial magnetic stimulation (TMS) and transcranial direct current stimulation (tDCS) [4].

Although results are variable [5], DBS has reported positive results over the motor function, especially on the motor symptoms of Parkinson's disease. However, DBS is a technique that needs the implantation of the electrodes on the stimulated area, which is associated with the typical risk derived from surgery, as infections. Therefore, there is an increasing tendence on the search for non-invasive brain stimulation techniques, which can modulate the motor function avoiding those risks.

Hence, NiBS are characterized for its easy and safe use and relatively cheap price, demonstrating also successful results in the treatment of neurological and psychiatric alterations [4]. In the last decades, TMS has been the most researched and developed neuromodulation technique. TMS generates fast changes in the magnetic field delivering electrical currents through the brain, allowing the specific modulation of the cortical excitability through the initiation of action potentials [6]. Multiple studies have already shown its efficacy and safe use for the treatment of multiple pathologies [7], serving also as a useful tool for the functional location of brain areas, especially regarding the motor cortex $[8,9]$. However, TMS requires the participation of the participant, and due to its functioning, it is difficult to perform a sham condition, which is highly desirable especially in the research field. In addition, TMS produces in most of the cases undesirable side-effects, as headache [10].

Therefore, the tDCS technique is attracting a strong interest in the neuroscience research field. $\mathrm{tDCS}$ has supposed a revolution in the last 15 years of research, solving most of the disadvantages of TMS [10]. tDCS is a neuromodulation tool consisting on a battery connected to two electrodes, the anode and cathode, which are placed directly over the brain scalp and over extracephalic regions. The current flows between both electrodes and induces the depolarization or hyperpolarization of the membrane of the underlying neurons, which depends of the anodal or cathodal nature of the electrode [11], altering the neuronal excitability resulting in the modification of the brain activity [12]. This device is completely portable, as it is provided by built-in rechargeable battery with duration of approximately $6 \mathrm{~h}$ stimulation time at $1 \mathrm{~mA}(0.5-1.5 \mathrm{~W}$ of power consumption), and needs approximately $7 \mathrm{~h}$ for complete recharging. In addition, including battery, it has a weight of $0.8 \mathrm{~kg}$. Its portability is one of the biggest advantages of tDCS in the context of NiBS. Therefore, tDCS can be considered as a suitable complementary technique on motor rehabilitation therapy, allowing its application in different contexes, during the motor training and even combined with aerobic exercise [13, 14].

This non-invasive brain manipulation has opened the doors for a variety of potential treatments for the major neurological and psychiatry diseases [15], as depression [16], 
schizophrenia [17], Obsessive-Compulsive disorder [18] and addictions [19], among others.

However, motor functions are the major target for clinical and non-clinical studies regarding tDCS, serving mainly as a potential tool in post-stroke rehabilitation [20], but also in pathologies like Parkinson's disease [21]. In addition, numerous studies have shown that $\mathrm{tDCS}$ produces changes in the brain plasticity processes, generating longlasting effects that enhances even further its applicability in the neurorehabilitation field $[22,23]$.

The purpose of this review is to assess the current and future stage of tDCS regarding its use on the human motor function, identifying the empirical cues that point out its benefits as well as its potential limitation, providing a comprehensive framework for designing future research in the field of brain stimulation with tDCS and human motor rehabilitation. The present review is divided in four parts. The first part is based on a detailed definition on what we know about tDCS, the protocols of montage and parameters of stimulation, comprising the mechanisms of action of tDCS, what differs tDCS from other non-invasive neuromodulation techniques, and the main need to-know safety standards. Given the conciseness of this first part, we will present the recent studies focusing exclusively on the empirical data obtained from the use of tDCS in the human motor function, regarding, in the second part, healthy humans; in the third part, its clinical application on deteriorated human motor functions across different pathologies as Parkinson disease, stroke and cerebral palsy. Finally, in the fourth part of this review, we will discuss the main current issues of tDCS applied on the human motor function.

\section{Understanding and differentiating tDCS Definition of tDCS}

Transcranial direct current stimulation is a non-invasive neurostimulation technique that delivers a weak direct current towards the cortical areas situated under two opposite electrodes: depending on the aim of the study, the "active electrode" is the one located on the target area, and the other one is the "reference electrode". These electrodes are connected to a 9-volt battery and covered by conductive sponges soaked in saline or other conductive media $[24,25]$. When both electrodes are located over a conductive area, as the scalp, a direct current flows between the anode and the cathode, generating specific changes in the cortical excitability of the underlying tissue [26]. These changes can be manifested into behavioral changes and even neuroplasticity might be generated under the use of tDCS through long-term potentiation (LTP)-like processes [27]. Therefore, this technique has attracted a great attention in the past century in the area of neuroscience research and neurorehabilitation.

\section{Effective stimulation parameters and montage protocol}

One of the key points in the practical use of tDCS is the choice of the correct stimulation parameters. For a safe and effective use of tDCS, it is important to delimit the current intensity, which is generally expressed in milliamps $-\mathrm{mA}$, but also in amps-A and/or microamps $-\mu \mathrm{A}$. In research, the current intensity is selected normally in a range from 0.5 to $2 \mathrm{~mA}[12]$. 
The other most important stimulation parameter is the size of the electrodes, which varies between $4 \times 4\left(16 \mathrm{~cm}^{2}\right), 5 \times 5\left(25 \mathrm{~cm}^{2}\right), 5 \times 7\left(35 \mathrm{~cm}^{2}\right)$ and $6 \times 6\left(36 \mathrm{~cm}^{2}\right)$ [24]. However, the current intensity and the electrode size are two interrelated parameters, which lead to the current density parameter. The current density is the result of the current intensity divided by the total surface volume that the electrode occupies, and it is expressed in research as $\mu \mathrm{A} / \mathrm{cm}^{2}, \mathrm{~mA} / \mathrm{cm}^{2}$ and $\mathrm{A} / \mathrm{cm}^{2}$ [28], being the most used range between 0.028 and $0.06 \mathrm{~mA} / \mathrm{cm}^{2}$ [28]. Smaller electrodes might be more efficient [24]. For instance, in a study that compared three electrode sizes $\left(12 \mathrm{~m}^{2}, 34 \mathrm{~cm}^{2}\right.$ and $\left.35 \mathrm{~cm}^{2}\right)$ while maintaining the same current density, the anodal tDCS with a $12 \mathrm{~cm}^{2}$ active electrode showed a greater spatial focality of the stimulated area, and evoked larger corticospinal changes, expressed by higher motor evoked potentials (MEPs) [29].

The location of the active electrode is generally determined by the international electroencephalogram (EEG) 10-20 System [30], and it is generally placed on the area that represents the motor cortex $(\mathrm{C} 3-\mathrm{C} 4)$. In the major studies regarding motor regions, the reference electrode has been placed over the contralateral orbit (just above the contralateral eye) [21], but it is also usually placed on extracephalic regions (neck, arms, chin, etc.) [12]. Recent studies, especially focused on stroke patients, have determined that bihemispheric stimulation, with the active electrode on the damaged hemisphere, and the reference electrode on the healthy hemisphere, could contribute to the reduction of the stroke motor symptoms, probably due to the reestablishment of the abnormal interhemispheric inhibitory interactions after stroke, reducing the increased activation of intact ipsilesional primary and adjacent nonprimary motor regions [31].

tDCS has its largest effects under the electrodes [32], however, studies with functional magnetic resonance (fMRI) and positron emission topography (PET) have showed that the stimulation generates constant and generalized effects in other areas of the CNS [33]. EEG results point in the same direction [34]. That means that the stimulation of one area will probably affect other brain areas throughout neural circuit networks [35]. This is not surprising due to the complex anatomy and interconnectivity of the human CNS, but it evidences the necessity of an exhaustive analysis of the stimulated structure and its relationship with adjacent areas [36, 37].

\section{What differs tDCS from other non-invasive neurostimulation techniques}

Deep brain stimulation is a neurostimulation technique that works thanks to the implantation of electrodes in the precise target brain locations, showing until now suitable results for the treatment of motor [38]. However, tDCS differs from DBS for the fact that it does not need surgery for its application. Therefore, the present technique is able to stimulate the brain in a non-invasive way, which reduces risks and possible side effects. Nevertheless, DBS is able to reach deep brain areas, while tDCS reaches only cortical areas [12].

As mentioned before, TMS is also a well-studied NiBS technique that has shown numerous successful results in the area of neurostimulation in healthy, as well as in clinical studies. However, TMS frequently produces headache in most of the users [39], whereas tDCS can provoke itchiness in the location of the electrodes and not greater side effects have been demonstrated until now [12, 40]. In addition, TMS is a relative noisy device, whereas tDCS is a portable, totally silent and discrete device that does not 
need the collaboration of the user, which facilitates the creation of a sham condition, and consequently, its usage in the research field. This sham condition is generally performed with real stimulation, but only the first minute, and subject do not perceived it as different from the stimulation condition [41]. As we will see in the following section, the mechanisms of action of tCDS are different than those of other neuromodulation technique, as, in contrast with TMS, tDCS does not induce directly neuronal action potentials, because static fields in this range do not profit the fast depolarization needed to produce action potentials in neural membranes [12]. Consequently, tDCS should always be administered together with motor training tasks, showing its highest effects when applied before or during the task [42]. A recent study also has compared the electric field distribution in TMS and tDCS in the motor cortex showing that both techniques induce electric fields, but with different directions: the field in tDCS is mainly perpendicular to the cortical surface, while in TMS the field is regularly parallel to it [43].

\section{Mechanism of action of tCDS}

Despite the exact mechanisms of action of tDCS are still under study, it is widely established that the current flows between the anode and the cathode produce a modulation of the resting membrane potential of the underlying neurons of the stimulated area. In the case of the anode, the neuronal excitability generally increases and the cell membranes are depolarized, while in the area of the cathode, the excitability is dropped down and therefore producing a hyperpolarization of the underlying tissue. However, it is important to highlight that, depending on the direction and the current intensity, this effects can be inverted [12]. After the stimulation, the MEPs levels produced by a single 10 min session can last until $60 \mathrm{~min}$ after the stimulation [44].

Short as well as long lasting effects produced after the application of tDCS are important in order to differentiate its effects: short term effects are interesting in the research field, while long term effects are necessary to be considered as part of a treatment in the clinical field. Short-term effects seem to be produced by local changes in the ionic concentrations, specific alterations in transmembrane proteins and electrolysis related to slight changes in the hydrogen protons concentration [34]. Actually, recent studies have observed a large accumulation of myoinositol into the phospholipid membrane after anodal tDCS through proton magnetic resonance spectroscopy [45] and a significant augmentation of oxyhemoglobin concentrations after $1 \mathrm{~mA}$ of anodal tDCS by near-infrared spectography [46], showing also changes in the cerebral blood flow when applied over the primary motor cortex [47].

The electrical current produced by tDCS modulates the resting membrane potential of a variety of neuronal population, as pyramidal cells, and interneurons (gabaergic). This leads to substantial changes in the field potential; and these changes raise or drop the firing rate up or down, depending on the nature of the electrode [48].

In consonance with this, several studies have showed sustained neurochemical differences between both types of stimulation, anodal and cathodal. Many investigations are in agreement with the fact that the excitatory effects of tDCS are mediated, at least in part, by an important reduction of the GABAergic activity and by the facilitation of the NMDA glutamatergic receptors [49]. On the other hand, it seems that cathodal tDCS is mediated by an important reduction of the excitation of the glutamatergic system [50]. 
The key point of tDCS to be considered as a tool in neurorehabilitation is the possibility of producing long-term effects. These long-term effects are mediated by the neuroplasticity generated by the application of tDCS, which has been confirmed in a variety of animal and human studies [51-53]. The consolidation of learning during the use of tDCS is possibly mediated by catecholaminergic transmitters, and specially adrenergic ones, being the catecholaminergic effects NMDA receptor-dependent [54]. The positive effects produced by the modulation of the glutamatergic system could eventually lead to the release of the brain-derived neurotrophic factor (BDNF) [55]. In fact, tDCS has shown to change the BDNF [56] promoting the BDNF-dependent synaptic plasticity [22].

\section{Safety considerations before using tDCS}

The main facts that determine the safe and correct use of this technique are the current density, the duration of the stimulation, the number of sessions and the inter-session time $[26,57]$.

Considering that the high current density is concentrated in the edges of the electrode, special attention needs to be payed on the intensity and characteristics of the electrodes; actually, some studies have developed circular electrodes instead of square-shaped ones. This has to be added to the importance of the control of the saline quantity incorporated to both sponges, which facilitates the electric current transmission [58].

Indirect biomarkers of brain damage did not change after the application of tDCS: the serum levels of the molecular markers of neuronal lesion ( $\mathrm{N}$-acetylasperate) as well as the levels of other related metabolite contents remained stable after the application of tDCS [45]. Also no adverse effects were found on the heart function [59] and no convulsive effects have been related to tDCS [40].

In a safety study, $1 \mathrm{~mA}$ of tDCS was applied across 567 sessions on 102 healthy participants, and no relevant adverse effects were seen, showing tDCS better side effects than previous studies with TMS. tDCS seems to be a safe and suitable-for-use methodology that produces side effects only in punctual occasions [60]. Some side effects that can commonly been observed are soft itching, mild burning or slight pain felt under the electrodes. In addition, subtle tingle and moderate fatigue. Less common, it is possible to experiment slight headache, difficulty to concentration, nausea and sleep disturbances [60]. Depending on the electrode shape and size, infrequently, tDCS can produce a skinburning lesion [61]. However, the skin lesion would have any consequence for the cerebral tissue [62]. For the correct electrical conduction between the electrodes and the skin, saline has demonstrated to be safer than tap water. If electrode gel is used, the quantity has to be large enough to avoid the direct contact between the electrodes and the skin. However, the most important issue to avoid skin damage is to ensure that the skin surface is not dry [63].

\section{Effect of tDCS on the motor function in healthy population}

This second part of the review will focus on the most prominent effect found on the application of tDCS on the human motor function on healthy participants. These outcomes are the most promising steps forward to reach a limited and effective use of tDCS on the neurorehabilitation field. The principal key facts of the studies exposed in this section can be found in Additional file 1: Table S1. 


\section{Effect of tDCS on lower limbs}

The stimulation on the primary motor cortex (M1), when applied over the contralateral hemisphere of the target leg has reported positive results. For instance, in the study of Sriraman et al. [13], $15 \mathrm{~min}$ of $1 \mathrm{~mA}$ of anodal tDCS showed better results $24 \mathrm{~h}$ after the stimulation than the sham condition. In addition, when the stimulation was applied together with an ankle motor task, the results obtained where even better. These results were measured by the accuracy showed on a manipulandum for ankle motor testing and practice, were the participants performed an ankle dorsiflexion and plantarflexion to match a sinusoidal wave on the computer screen as accurately as possible.

Moreover, in a study where the intensity was configured up to $2 \mathrm{~mA}$, the anodal stimulation of the M1 contralateral to the target leg during $10 \mathrm{~min}$, reported an increased positive work generation during propulsion, step length and slow walking speed, enhancements that lasted until $45 \mathrm{~min}$ after the stimulation. In the same study, bicephalic and monocephalic stimulation configuration where compared, showing bicephalic configuration stronger effects than the monocephalic one. However, large inter-individual variability was observed [64].

But when concerning human motor modulation, not only the motor cortex is a stimulation target, also the stimulation of the cerebellum is a potential target area for the motor rehabilitation. Galea et al. [65], applied anodal tDCS (atDCS) and cathodal tDCS (ctDCS) on the right cerebellum cortex during $25 \mathrm{~min}$, and obtained a tone inhibition after cathodal stimulation and an increase after the anodal stimulation. In addition ctDCS decreased the cerebellum-brain inhibition (CBI) action, and augmented after atDCS.

For instance, Jayaram et al. [66] applied anodal and cathodal tDCS on both cerebellum hemispheres ( $3 \mathrm{~cm}$ lateral to the inion) during $15 \mathrm{~min}$ with a current intensity of $2 \mathrm{~mA}$. atDCS increased the rate of walking adaptation, while ctDCS had the opposite effect. In the previously mentioned study, atDCS was recognized as a CBI depressant, which is contradictory. Therefore, additional research is needed in order to clarify this paradoxical effect (for possible hypothesis, see Jayaram et al. [66]).

Neuroimaging studies give us the possibility to confirm the changes in the brain beyond the behavioral improvements. In fact, in a study that stimulated with atDCS the left M1 with $2 \mathrm{~mA}$, during $15 \mathrm{~min}$, across 4 days [67], fMRI showed an activation of the right supplementary motor area and a decrease of the activation of the contralateral hemisphere. But also a bilateral activation of diverse structures such as the anterior cingulate gyrus, the right middle/superior temporal gyrus, middle/superior frontal gyrus and the primary and secondary somatosensory cortices were detected. These results indicate that atDCS changes the excitability of the corticospinal pathway to both legs by networks, which enroll many areas besides M1.

Added to this, MEPs and muscular outcomes by electromyography (EMG) have been studied in healthy humans. Thus, Madhavan and Stinear [68] have demonstrated that, after the application of atDCS on both M1 (leg representation), but in separated sessions and with a current intensity of $0.5 \mathrm{~mA}\left(0.06 \mathrm{~mA} / \mathrm{cm}^{2}\right)$ during $10 \mathrm{~min}$, strong intervariability data measured in 40 muscle pairs (10 subjects $\times 2$ sessions $\times 2$ muscle pairs) was observed. Instead, a mean change in cortical excitability of $60 \%$ on stimulated areas was also found, but induced between-hemisphere opposite sign modulation, as authors 
previously hypothesized, disturbed most part of physiological outcomes. This is a clear proof of the complexity of human cortex. Instead, we consider that a higher current intensity could be needed in order to induce strongest contralateral modulation in both MEPs and EMGs, despite of the fact that similar current density was demonstrated as enough to induce consistent MEPs changes by Jeffery et al. [69]. These authors implemented a current intensity of $2 \mathrm{~mA}$ during $10 \mathrm{~min}$ on the M1 (leg representation), with an increase in MEPs amplitude of 59\% at rest and 35\% in contraction phase, with effects further to $60 \mathrm{~min}$ after stimulation. All these data taken together indicate that, even being the current density value very important, every single feature of the stimulation procedure has to be studied and planned in depth.

\section{Effect of tDCS on upper limbs}

In order to predict the effects of tDCS on the primary motor cortex on an injured or under-used motor function, an experimental design widely used on healthy participants is the stimulation of the contralateral motor cortex of the non-dominant hand. The under-use of the left hand, by right-handed participants or the right hand by left-handed participants represents an effective model to study the effect of training complemented by tDCS on motor learning [70].

An example of the success of this kind of experimental design, is the study carried on in our laboratory (Sánchez-Kuhn et al. unpublished) in which a constant current of anodal $2 \mathrm{~mA}$ tDCS was administered during $20 \mathrm{~min}$ on the right motor cortex within three consecutive sessions, with an intersession time of $24 \mathrm{~h}$, during the training with the non-dominant hand on the sequential finger tapping task (SEQTAP). Participants were tested before the experiment, during the three training sessions, in the short term (20 min after), and in the long-term (8 days after). Findings showed a higher performance of the stimulated participants when compared to the sham group during the performance of the task, in the short-term, and also in the long-term. Other studies have also successfully improved the finger movement on healthy individuals by anodal tDCS [71].

The voluntary movement of responding to a stimulus can be modified, but also the motor suppression has been improved with anodal tDCS [72] which lets the doors open for the research of possible treatments for the compulsive behaviors or stereotypes manifested in the Obsessive-Compulsive disorder or in autism, among others.

\section{Effect of tDCS on the motor function in clinical population}

The following section will focus on the most remarkable effects found on the application of tDCS on the human motor function of clinical population. The reviewed pathologies have all in common the deterioration of the motor skills as a symptom or consequence of the disease. The principal key facts of the studies exposed in this section can be found in Additional file 2: Table S2.

\section{Stroke and tDCS}

Dysfunctions in the use of upper limbs and deficits in the functional walking are among the most common after stroke. Only $5 \%$ of adult post-stroke patients recover their full upper limb function [73]. Motor recovery after stroke is mostly dedicated to the intent 
to preserve the ipsilesional motor networks and the interactions between both hemispheres. tDCS seems to be able to modulate these processes [74]. Following this theory, it has been demonstrated that positive effects can be observed by the cathodal stimulation of the non-affected hemisphere, presumably due to the current flows property thanks to the undamaged intracortical networks [75].

In accordance with this approach, Lindenberg et al. [31] combined bicephalic stimulation (atDCS on ipsilateral M1 and ctDCS on contralesional M1) $(1.5 \mathrm{~mA} / 30 \mathrm{~min} / 5 \mathrm{ses}$ sions) with orthodox occupancy and physical therapy, obtaining an enhancement of the motor functions of chronic post-stroke patients when comparing with the sham condition. However, contrary data to this approach has been found. For instance, other study performed on healthy subjects showed that a single session of only atDCS or ctDCS $(1 \mathrm{~mA} / 20 \mathrm{~min})$ displayed greater effects over the level of MEPs than bicephalic stimulation [76].

In another way, a significant enhancement assessed in the Jebsen-Taylor hand function test (a specific hand function task for daily living activities) was observed after the application of atDCS on M1 ( $1 \mathrm{~mA} / 20 \mathrm{~min})$ on post-stroke patients with hemiparesis subsequent to first-ever unilateral stroke, but not on the sham condition, resulting in functional improvements in motor function of the paretic hand [77].

Similar unilateral tDCS effects have been also confirmed also on further functions deteriorated after stroke. For example, post-stroke aphasia has been chose as a key objective for tDCS intervention. Rosso et al. [78] demonstrated, after the application of ctDCS over the right Broca's area, an improvement in language performance in patients with aphasia in the chronic post-stroke phase, supporting the idea that ctDCS can suppress inhibitory inter-hemispheric influences from the right Broca's area to the affected one, and that inter-individual differences are crucial in the design of the methodology of effective stimulation processes. Those effects might be facilitated by GABAergic intracortical and inter-hemispheric function [79].

\section{Dysphagia and tDCS}

One of the possible motor dysfunctions derived from stroke is dysphagia, which is a high disrupting syndrome that consists basically on the impossibility of starting and accomplishing the voluntary or involuntary movement of swallowing. Dysphagia might be followed by serious consequences as nutritional problems, respiratory system issues and daily life deficits affecting the emotional and social areas of the patient [80, 81].

The primary motor cortex plays the principal role on the voluntary initiation of the swallowing process, and both hemispheres seem to be responsible for this behavior [82]. However, neuroimaging techniques showed that in most of the cases, the activation during the swallowing process was greater in one hemisphere than in the other, being this fact independent of handedness. Furthermore, this predominance was different between identical right-handed twins [83].

In the last years, studies have been developing the possibility of incorporate tDCS to the treatment of dysphagia (for review, see Sandrini and Cohen [84]). Kumar et al. [85] applied atDCS on the undamaged motor cortex $(2 \mathrm{~mA} / 30 \mathrm{~min} / 5$ sessions $)$ together with standardized swallowing training, finding a significant improvement of the Dysphagia Outcome and Severity Scale (DOSS) scores. Also Yang et al. [86] used atDCS 
( $1 \mathrm{~mA} / 20 \mathrm{~min} / 10$ sessions) but on the affected hemisphere, accurately, on the over the pharyngeal motor cortex, and measured the effects of atDCS by the functional dysphagia scale (FDS) using video fluoroscopic swallowing measure (VFSS) immediately after the intervention and three months later. Differences between the atDCS and the sham group emerged on the second evaluation.

In our laboratory (Sánchez-Kuhn et al. unpublished), we carried on a study over a poststroke cellebelar lesion patient who consequently developed dysphagia. This study combined the monocephalic $1 \mathrm{~mA}$ anodal tDCS stimulation during 16 sessions of 20 with swallowing training. However, only minor positive results were registered over dysphagia symptoms as well as over The swallowing quality of life questionnaire (SWAL-QoL). Nevertheless, diffusion tensor imaging (DTI) results showed a significant increase of the number of fibers and connections in the left cerebellum after the combined treatment of anodal tDCS over M1 and swallowing training. Therefore, tDCS delivers also information about the brain networks involving motor functions as the swallowing process.

\section{Parkinson's disease and tDCS}

Besides DBS has shown positive results on the treatment of Parkinson's disease (PD) (for review, see Hickey et al. [87]), many studies have reported positive results of tDCS on motor as well as cognitive symptoms of Parkinson's disease, data that is supported also by neurophysiological effects (for review, see Broeder et al. [88]). However, in the current section, we will focus on the particular effects of tDCS on motor deficits. Therefore, Fregni et al. [89] demonstrated that, with the application of atDCS $(1 \mathrm{~mA} / 20 \mathrm{~min} / 1$ session) on the left M1 of patients in OFF-state, a significant increase in MEPs were produced compared to sham condition. This effect was contrary after ctDCS, as ctDCS decreased the MEPs amplitude. These effects correlated also with motor enhancements (bradykinesia, tremor, rigidity, gait, postural instability etc.). Augmenting the number of sessions up to 5 , a study found also positive results after atDCS ( $2 \mathrm{~mA} / 20 \mathrm{~min}$ ) but in patients in $\mathrm{ON}$-state (phase when Parkinson's motor symptoms are generally under control) [90].

Recently, a study that induced dyskinesias (involuntary muscle movements that characterize the motor symptoms of Parkinson) with Levodopa in PD patients, found a reduction of the dyskinesias when administering bilateral atDCS $(2 \mathrm{~mA} / 20 \mathrm{~min} / 5$ sessions) in M1 as well as in the cerebellum [91].

In addition, tDCS has resulted in positive motor outcomes on the long-term, as seen in the study of Benninger et al. [21] where the group that received the stimulation improved bradykinesia in their upper extremities in both, the on and the off state, effect that was maintained for longer than 3 months.

\section{Multiple sclerosis/Amyotrophic lateral sclerosis and tDCS}

Few studies from 2010 have focused on different motor and cognitive effects of the application of tDCS in patients with multiple sclerosis (for review, see Mehta et al. [92]; Pérez-Fernández et al. [93]). Thus, Cuypers et al. [94] demonstrated that, after the application of atDCS with a current intensity of $1 \mathrm{~mA}$ during $20 \mathrm{~min}$ on M1 (first dorsal interosseous), contralateral to the more impaired hand, significant corticospinal excitability increase was observed evaluated by MEP variations, effect non-observed after 
sham stimulation. This cortical modulation triggered to a recruitment-curve plateau increase, something that could be explained by distal effects mediated by large-diameter myelinated axons. Nevertheless, no functional effects were studied. However, no motor improvement facilitation were observed by Meesen et al. [95] after atDCS with a current intensity of $1 \mathrm{~mA}$ during $20 \mathrm{~min}$ on contralateral to impaired hand M1, compared to sham condition. Further researches in motor function are needed.

It is interesting to point out that also positive sensory modulations have been observed after atDCS application in patients with multiple sclerosis. Mori et al. [96] demonstrated that, by applying atDCS with a current intensity of $2 \mathrm{~mA}$, during $20 \mathrm{~min} / 5$ consecutive daily stimulation on somatosensory cortex (S1), temporally ameliorated sensory deficits (spatial discrimination thresholds on the hypoesthetic hand) further to 2 weeks after treatment were observed in patients with multiple sclerosis. These sorts of positive sensory modulations have been observed also in pain self-sensation in patients with multiple sclerosis [97], after the application of atDCS with a current intensity of $2 \mathrm{~mA}$, during $20 \mathrm{~min} / 5$ consecutive daily stimulation on contralateral to somatic painful area M1, with a clear decrease of values in standardized pain scales.

On the other hand, there are very few studies of the application of tDCS on Amyotrophic lateral sclerosis (ALS). However, as Di Lazzaro et al. [98] pointed out, after the variable results of the application of TMS in patients with ALS, tDCS could be considered as a better intervention tool due to its longer-lasting effects on cortical excitability. Thus, and as a preliminary study, these authors showed no significant effects after ctDCS on M1 (the cortical representation of the first dorsal interosseous muscle), with a current intensity of $1 \mathrm{~mA}$ during $20 \mathrm{~min}$ on both hemispheres in two different patients. Related to this, Munneke et al. [99] demonstrated no significant cortical excitability variations after $1 \mathrm{~mA}$ ctDCS during 7, 11 and $15 \mathrm{~min}$. However, an important effect was observed in healthy subjects, indicating that patients with ALS could have less responsive corticospinal pathways to the inhibitory ctDCS effects. Such results were early demonstrated by Quartarone et al. [100] in both anodal and cathodal stimulation types. Nevertheless, it has been demonstrated that continuous theta burst stimulation (cTBS) by TMS can induce an inhibitory effect on corticospinal excitability in patients with ALS only after five daily sessions [101], so it is reasonable to postulate that repetitive ctDCS training could generate similar effects on patients with ALS.

\section{Spinal cord injury and tDCS}

After the numerous confirmations of the positive effects of tDCS and TMS on the management of neuropathic pain after spinal cord injury [92], the last investigations point towards tDCS as a target tool in the treatment for the motor-related consequences of spinal cord injury. Thus, Silva et al. [102] applied atDCS on both M1 (2 mA/12 min) in a subject with total chronic spinal cord injury and the results showed a general improvement in exercise tolerance by the specific measures undertaken in exercise time and power, perceived exertion, glucose levels, and the time needed to reach the heart rate threshold.

In the study of Murray et al. [103], after the application of atDCS on the left M1 (extensor carpi radialis muscle representation) in nine patients with chronic spinal cord injury ( $2 \mathrm{~mA} / 20 \mathrm{~min} / 3$ sessions), the authors observed an increase of $40 \%$ in the corticospinal 
excitability (MEPs) amplitude. This result was not reached with an intensity of $1 \mathrm{~mA}$. Despite of the high current density implemented in this work, no significant adverse effects were seen.

However, the best results in spinal cord injury were obtained applying directly the new technique of transcutaneous spinal direct current stimulation (tsDCS). Hence, Hubli et al. [104] located the active electrode longitudinally between the spinous processes T11 and T12 (2.5 mA/20 min). This intervention showed specific differences in spinal reflex behavior, where patients showed higher changes in spinal reflex amplitude after a-tsDCS than healthy subjects, exhibiting even better results than receiving a session of assisted walking in the driven gait orthosis "Lokomat". These results are evidenced by the changes that produced atsDCS in the conduction along the lemniscal pathway (specific somatosensory evoked potentials amplitude P30) in healthy subjects after an application of atsDCS over the spinous process (T10) $(2.5 \mathrm{~mA} / 15 \mathrm{~min})$ [105].

\section{Restless legs syndrome and tDCS}

The restless legs syndrome (RLS) is a sensorimotor neurological pathology whose main characteristic is periodic limb movements during sleep, which generates alterations in sleep [106]. This alteration has been insufficiently studied in tDCS approaches, and controversial data has emerged. However, Heide et al. [107] found that after the application of both atDCS and ctDCS over the spinal process T1 with a current intensity of $2.5 \mathrm{~mA}$ during 15 min in patients with RLS, an important decrease after anodal stimulation in spinal excitability was observed, conducting to clear reduction of restless symptoms in a VAS scale and in specific reflexes. Such effects were not observed after sham stimulation.

Nevertheless, such effects have not been observed after cortical stimulation [108]. Those authors implemented tDCS on bilateral M1 (CZ position, legs representation) with a current intensity of $2 \mathrm{~mA}$ during $20 \mathrm{~min}$ for 5 sessions/2 weeks. No significant differences were found between groups in the International RLS Group Rating Scale and the Clinical Global Impressions-Improvement. All these data together could indicate that, in this sort of pathologies, direct currents on the back could be a better rehabilitation procedure than cortex stimulation approach. However, further researches are needed.

\section{Cerebral palsy in children and tDCS}

Cerebral palsy is the most common motor disease in children, and it refers to permanent, motor development disorders owing to a primary brain lesion, causing secondary musculoskeletal problems and subsequently, constraining the daily living activities of the child [109].

Besides there are numerous studies reporting the safe application of tDCS on infancy special actions are needed when administering tDCS on children, as the current intensity, the density and the size of the electrodes (for review, see [110]).

As in the previous studies, the effects of tDCS on cerebral palsy are especially positive when the stimulation is administered in combination with motor rehabilitation. On a study with 24 children with cerebral palsy, the researches administered atDCS (1 $\mathrm{mA} / 20 \mathrm{~min} / 10$ sessions) combined with treadmill training on balance and functional performance. The Pediatric Balance Scale and the Pediatric Evaluation of Disability 
Inventory results showed positive effects on the balance score of the stimulated group, 1 and 4 weeks after the treatment [111].

Spasticity has been also a key target in the use of tDCS on children with cerebral palsy, as it is one of its most common symptoms [112]. Spasticity is defined as an upper motor neuron syndrome characterized by a velocity-dependent increase in the tonic stretch reflexes with amplified tendon jerks resulting from the hyperexcitability of this reflex [112]. Concerning the importance of this symptom in cerebral palsy, Aree-Uea et al. [113] conducted a study with 46 children between 8 and 18 years with cerebral palsy. The treatment consisted of a stimulation of atDCS over the left primary motor cortex $(1 \mathrm{~mA} / 20 \mathrm{~min} / 5$ sessions) added to stretching exercises during five consecutive sessions. Spasticity was measured before and 24 and $48 \mathrm{~h}$ after the treatment. Results showed a reduction of finger spasticity immediately after the treatment, a reduction of the elbow spasticity also immediately and 24 after the treatment and a reduction of wrist spasticity immediately, 24 and $48 \mathrm{~h}$ after the treatment with atDCS.

Moreover, a number of promising studies is combining tDCS with virtual reality training, presenting optimistic results in researches concerning motor abilities, as for example, on the improvement of the body sway velocity [114], and also regarding spatiotemporal gait variables (velocity and cadence) and gross motor function and mobility [115]. Furthermore, in this last study anodal tDCS led to a significant change in motor cortex plasticity, as evidenced by the increase in the amplitude of the motor evoked potential. The experiential learning facilitated by virtual reality training, where the stimulus are visual, and provide feedback, augment the motivation of the children, which can lead in even higher positive effects of the stimulation with tDCS (for review, see [116]). Therefore, the combination of motor training with virtual reality and tDCS could constitute a new potential neurorehabilitation therapy for children with cerebral palsy.

\section{Limitations and future guidelines}

Even though the extend literature available about tDCS, there are still several limitations that have to be taken into account. As mentioned before, the parameters of stimulation must be exactly defined in order to reach the desired effects. This is not an easy task concerning that not always higher intensity and a longer stimulation means larger effects of tDCS. In addition, the measure of the improvements should be compared with the results in other tasks, to ensure the specific motor, behavioral or cognitive effects of the stimulation. Furthermore, to consider tDCS as a neurorehabilitation tool, it is essential to find a long-lasting effect of tDCS that ensures improvements not only over hours or days, but also month and even years (for reviewing this and other tDCS limitations, [117]).

However, one of the most important issues concerning the effective use of tDCS is the interindividual variability found across the data until now. The effects of tDCS are brain state-dependent [63], consequently, the amount and direction of its effects is critically depending on the previous physiological state of the target neural structures $[63,118]$. Wiethoff et al. [119] found a large variability regarding corticospinal excitability response to tDCS across 53 healthy subjects. According to the most recent studies regarding the interindividual variability there are some different hypothesis why tDCS might produce different effects. Up to date, the tendence of the results show that those participants with lower baseline performance result more benefitted from tDCS. Moreover, in our 
laboratory (Sánchez-Kuhn et al. unpublished), we conducted a study including healthy participants with and without previous musical training, who performed a SEQTAP task with the non-dominant hand while being stimulated over the contralateral primary motor cortex. Among healthy subjects, musicians offer an outstanding human model for studying brain properties of acquiring, practicing, and maintaining specialized motor skills [120]. Our results showed that non-musicians resulted benefited from the anodal stimulation, scoring better than the sham group during, in the short-term and in the long-term in the task, while musicians did not resulted benefited from tDCS when compared to their sham group. The better effect on participants with an initial lower performance has different hypothesis. Those purposes are: (1) the type of registration or task [121], (2) the ceiling effect produced as a consequence of a not enough demanding task for over skilled participants [122] and (3) the lower activation of the primary motor cortex, supplementary motor area, premotor cortex and superior parietal lobule [123], indicating a reduced use of primarily motor cortex, as a lower level of brain activity is required [124, 125]. In addition, a study found that non-schizophrenic first-degree relatives of schizophrenia patients had altered MEP response to cathodal tDCS on M1, compared to non-related healthy participants [126]. Assumed the high heritability of schizophrenia, these results enhance the role of genetic variability in the interindividual variability of the response to tDCS.

Therefore, the type of registration task, the baseline performance level, the specific brain areas used for the task, as well as the genetic variability, are facts that need to be taken into account along the application of tDCS. At this point it is important to highlight the need to develop more robust protocols, understanding the individual factors that determine responsiveness.

Other of the principal lacks of tDCS is the extension of the area that results stimulated during its application [117]. Conventional parameters of tDCS may modulate further areas as the specific target placement. For instance, Lang et al. [127] presented a neuroimaging study in which the stimulation of the left primary motor and right frontopolar cortex showed to increase also regional cerebral blood flow (rCBF) on other peripherals and underlying areas.

In response to this demand, a recent improvement of the present technique, namely high definition transcranial direct current stimulation (HD tDCS), has emerged in the field of neuromodulation presenting considerable enhancements. Primarily, HD tDCS electrodes are much smaller than those used by tDCS. Conventional tDCS uses mainly 16-35 $\mathrm{cm}^{2}$ electrodes [4] whereas HD tDCS uses $\sim 25 \pm 2.5 \mathrm{~mm}^{2}$ electrodes provided with a plastic holder, that additionally enhances security. The new configuration of HD tDCS also allows the settlement of more than one anode and cathode, which appears to result in a mayor effect of tDCS and an increase of focality. For instance, the study of Kuo et al. [128] compared a $4 \times 1$ HD tDCS ring configuration (compounded by four cathodes and one central anode) with a conventional tDCS stimulation of rectangular sponge pads by measuring the motor cortical excitability. In both cases, the current strength was $2 \mathrm{~mA}$ and the duration of the stimulation $10 \mathrm{~min}$. Results showed that anodal as well as cathodal tDCS increased or decreased respectively cortico-spinal excitability reaching an effect immediately after the application, while HD-tDCS showed an effect 30 min later. However, the excitability alterations obtained by the conventional mechanism vanished 
120 min post tDCS. Interestingly, HD tDCS lasted an effect over the MEP amplitude up to $2 \mathrm{~h}$ after the stimulation. Additionally, a better spatial focality using the ring electrode versus conventional rectangular pads was shown by Datta et al. [129].

It is also important to remark that HD tDCS presents the possibility of being applied together with neuroimaging techniques [130], which gives the opportunity to access to detailed information about the cortical activity underlying the stimulation.

However, HD tDCS presents a deficiency compared to conventional tDCS, as it produces a greater scalp sensation during the stimulation, which remains also stable along the stimulation. In this aspect, HD tDCS presents a difficulty for its use on research, as the sham condition traditionally used with tDCS - namely, to administer the stimulation only the first minute-can be difficulty applied without resulting differentiated by the subjects. However, Garnett and Ouden [131] recently validated a sham condition for use in HD tDCS: the anodes and cathodes are located in the same position as in the stimulation condition, but the current direction is changed. The current crosses the scalp in a superficial way, creating in the subject a sensation of stimulation effect, but not reaching cortical areas. Subjects were not able then, to distinguish the stimulation from the sham condition.

Finally, it is important to consider the different effects of HD tDCS in adults and children, as the effect of HD tDCS appears to be stronger in children than in adults. In a study carried on by Minhas et al. [110] comparing the effects HD tDCS on adults and children, the peak electric field of the $4 \times 1$ high-definition ring configuration was 0.16 and $0.56 \mathrm{~V} / \mathrm{m}$ (for a disc center to disc center radius of $5 \mathrm{~cm}$ ), in the adult and child respectively for a $1 \mathrm{~mA}$ current stimulation. In addition, modulation of the cortical tissue appeared to extend much deeper (toward the ventricles) at $1.5 \mathrm{~mA}$ of current in the child compared to the adult. Therefore, lower parameters have to be applied by using HD tDCS on children.

To sum up, more research about HD tDCS needs to be done in order to define clearly its effects on cortical excitability. However, the fact that it is compatible with the online recording of neuroimaging techniques will allow its study much more easily. On the other hand, it would be desirable to reach less or no-sensation of the stimulation, improving the subject or patient's comfort and providing the homogeneity between the stimulated and the sham condition. At any rate, HD tDCS is a promising technique that improves the neuromodulation in terms of focality, plasticity and security.

\section{Conclusions}

In the last decade, the advantages of tDCS and its neuromodulation properties have been widely confirmed. In addition, its low side effects, easy management, well-established sham condition and relative low price are crucial keys in order to understand the big attention that tDCS has attracted in the research area in the last years [132].

The number of possible usages of tDCS is enormous, involving the modulation of many behaviors and neurological processes. As seen in the present review, this fact is visible in healthy subjects as well as in patients with diverse neuropathologies, being the neuronal plasticity effect of tDCS its main promising property for its consolidation as a future neurorehabilitation tool. Looking at the most prominent results of tDCS up to date, it is possible to conclude that the most efficient protocols in order to intervent 
over human motor function, in healthy, as well as in clinical population, involve repetitive sessions of tDCS rather than single sessions, and the intersession time should be at least of $24 \mathrm{~h}$. In addition, these tDCS sessions might report more positive results if they are accompanied by neurorehabilitation, specifically, physical therapy or motor training with the target body part, which ought be performed during the administration of $\mathrm{tDCS}$, if possible, or right after. Regarding the intensity of the stimulation, it should range from 1 to $2 \mathrm{~mA}$, but being not higher as $1 \mathrm{~mA}$ in children. Besides the duration of the stimulation of 15 and $30 \mathrm{~min}$ has reported positive results, the most used duration time is 20 min. monocephalic anodal tDCS has reported in general, more and better results than bicephalic or cathodal tDCS, and the stimulated areas vary among the corresponding motor cortex area, predominantly, and the cerebellum.

However, the improvement of complementary neuroimaging techniques and scanners with a better neuroanatomical resolution is fundamental in order to augment the knowledge of the basic neuroanatomical/functional brain structures, and consequently, enhance the reliably of the data generated by tDCS [70].

At a microscopic level, it is crucial to keep improving the researching on the biochemical bases that compound the mechanism of action of tDCS, due to the current evidence is still insufficient to set up a complete theory about its modulatory action over the human brain mechanisms [133]. In addition, it is important also to develop further sophisticated methodologies for the analysis of the axon orientation, the dendritic arborization, the role of astrocytes and the electrical field threshold of cortical cells [134].

As seen before, it is crucial to keep on studying the variables responsible for the big variability that $\mathrm{tDCS}$ presents. The interaction between the state of brain and the stimulation needs to be studied carefully in order to reach successfully effects of tDCS. In addition, tDCS could be also interesting as a modulator of pharmacological treatments [135].

The advantage of the portability of tDCS has differentiate this device from other neuromodulation techniques, permitting its application together with a variety of motor trainings in different contexes. Moreover, research should focus on the developing of even smaller and light-weighting tDCS equipments, as miniature tDCS devices [136] in order to improve its portability.

Finally, novel devices could supply the traditional tDCS methodology, representing the future of non-invasive neurological interventions. Therefore, as we have seen, HD-tDCS is an evolution of standard tDCS that provides a more focalized, safe and specific stimulation $[69,128]$.

Besides there is still research to carry on regarding the delimitation of even more effective, safe and long-lasting stimulation parameters, tDCS has demonstrated to be a high promising neuromodulation tool which is able to amplify the improvements seen along the rehabilitation of numerous motor functions.

\section{Additional files}

Additional file 1: Table S1. "Effects of tDCS on the motor function in healthy population", summarizing the most relevant results regarding the application of tDCS on the motor function in healthy participants obtained in the mentioned studies of the present review.

Additional file 2: Table S2. "Effects of tDCS on the motor function in clinical population", summarizing the most relevant results regarding the application of tDCS on the motor function in clinical subjects obtained in the mentioned studies of the present review. 


\section{Declarations}

Authors' contributions

ASK performed the searching of the literature, writing, and made the summary tables. CPF performed the searching of the literature and writing. PF and RC performed the design and scope of the review. FSS was the main conductor of the work and performed the design and scope of the review. All authors read and approved the final manuscript.

\section{Author details}

${ }^{1}$ University of Almería, Almería, Spain. ${ }^{2}$ Instituto de Neurorehabilitación Infantil InPaula, Almería, Spain.

\section{Acknowledgements}

Not applicable.

\section{Competing interests}

The authors declare that they have no competing interests.

\section{Availability of data and materials}

Data sharing not applicable to this article as no datasets were generated or analyzed during the current study.

\section{Funding}

This paper was funded by the grants from the Ministerio Economía y Competitividad, Spanish Government: Num: PSI2014-55785-C2-1-R and Num: PSI2015-70037-R allowing the adequate infrastructures for working on an effective search of literature, writing and publication. The publication costs were funded by the Grant Num.: PSI2015-70037-R.

\section{About this supplement}

This article has been published as part of BioMedical Engineering OnLine Volume 16 Supplement 1, 2017: Selected articles from the 4th International Work-Conference on Bioinformatics and Biomedical Engineering-IWBBIO 2016. The full contents of the supplement are available online at https://biomedical-engineering-online.biomedcentral.com/articles/ supplements/volume-16-supplement-1.

\section{Publisher's Note}

Springer Nature remains neutral with regard to jurisdictional claims in published maps and institutional affiliations.

Published: 18 August 2017

\section{References}

1. Llinás RR. The intrinsic electrophysiological properties of mammalian neurons: insights into central nervous system function. Science. 1988;242(4886):1654-64. doi:10.1126/science.3059497.

2. Kellaway P. The part played by electric fish in the early history of bioelectricity and electrotherapy. Bull Hist Med. 1946;20(2):112-137. http://europepmc.org/abstract/MED/20277440\%5Cnhttp://www.ncbi.nlm.nih.gov/ pubmed/20277440.

3. Zago S, Ferrucci R, Fregni F, Priori A. Bartholow, Sciamanna, Alberti: pioneers in the electrical stimulation of the exposed human cerebral cortex. Neuroscientist. 2008;14(5):521-8. doi:10.1177/1073858407311101.

4. Miniussi C, Paulus W, Rossini P. Transcranial brain stimulation. Boca Raton: CRC Press, Taylor \& Francis group; 2012. https://books.google.es/books?hl=es\&lr=\&id=McDLXdwGlalC\&oi=fnd\&pg=PP1\&dq=miniussi+palaus $+2012+$ transcranial\&ots=SPOxmpOfdo\&sig=dGtv7Y809mB0hn680MMr-Z7Atrc\#v=onepage\&q\&f=false.

5. Hershey T, Wu J, Weaver PM, et al. Unilateral vs. bilateral STN DBS effects on working memory and motor function in Parkinson disease. Exp Neurol. 2008;210(2):402-8. doi:10.1016/j.expneurol.2007.11.011.

6. Pascual-Leone A, Tormos JM, Keenan J, Tarazona F, Cañete C, Catalá MD. Study and modulation of human cortical excitability with transcranial magnetic stimulation. J Clin Neurophysiol. 1998;15:333-43. doi:10.1097/00004691-199807000-00005.

7. Kobayashi M, Pascual-Leone A. Transcranial magnetic stimulation in neurology. Lancet Neurol. 2003;2(3):145-56. doi:10.1016/S1474-4422(03)00321-1.

8. Espadaler J, Rogić M, Deletis V, Leon A, Quijada C, Conesa G. Representation of cricothyroid muscles at the primary motor cortex (M1) in healthy subjects, mapped by navigated transcranial magnetic stimulation (nTMS). Clin Neurophysiol. 2012;123(11):2205-11. doi:10.1016/j.clinph.2012.04.008.

9. Vitikainen AM, Salli E, Lioumis P, Mäkelä JP, Metsähonkala L. Applicability of nTMS in locating the motor cortical representation areas in patients with epilepsy. Acta Neurochir (Wien). 2013;155(3):507-18. doi:10.1007/ s00701-012-1609-5.

10. Priori A, Hallett M, Rothwell JC. Repetitive transcranial magnetic stimulation or transcranial direct current stimulation? Brain Stimul. 2009;2(4):241-5. doi:10.1016/j.brs.2009.02.004.

11. Zaghi S, Acar M, Hultgren B, Boggio PS, Fregni F. Noninvasive brain stimulation with low-intensity electrical currents: putative mechanisms of action for direct and alternating current stimulation. Neuroscientist. 2010;16(3):285-307. doi:10.1177/1073858409336227.

12. Nitsche MA, Cohen LG, Wassermann EM, et al. Transcranial direct current stimulation: state of the art 2008. Brain Stimul. 2008;1(3):206-23. doi:10.1016/j.brs.2008.06.004.

13. Sriraman A, Oishi T, Madhavan S. Timing-dependent priming effects of tDCS on ankle motor skill learning. Brain Res. 2014;1581:23-9. doi:10.1016/j.brainres.2014.07.021. 
14. Mendonca ME, Simis M, Grecco LC, Battistella LR, Baptista AF, Fregni F. Transcranial direct current stimulation combined with aerobic exercise to optimize analgesic responses in fibromyalgia: a randomized placebo-controlled clinical trial. Front Hum Neurosci. 2016;10(March):68. doi:10.3389/fnhum.2016.00068.

15. Tortella G, Casati R, Aparicio LVM, et al. Transcranial direct current stimulation in psychiatric disorders. World J Psychiatry. 2015;5(1):88.

16. Nitsche MA, Boggio PS, Fregni F, Pascual-Leone A. Treatment of depression with transcranial direct current stimulation (tDCS): a review. Exp Neurol. 2009;219(1):14-9. doi:10.1016/j.expneurol.2009.03.038.

17. Brunelin J, Mondino M, Gassab L, et al. Examining transcranial direct-current stimulation (tDCS) as a treatment for hallucinations in schizophrenia. Am J Psychiatry. 2012;169(7):719-24. doi:10.1176/appi.ajp.2012.11071091.

18. Volpato C, Piccione F, Cavinato M, et al. Modulation of affective symptoms and resting state activity by brain stimulation in a treatment-resistant case of obsessive-compulsive disorder. Neurocase. 2013;19(4):360-70. doi:10. 1080/13554794.2012.667131.

19. Nakamura-Palacios EM, Lopes IBC, Souza RA, et al. Ventral medial prefrontal cortex (VmPFC) as a target of the dorsolateral prefrontal modulation by transcranial direct current stimulation (tDCS) in drug addiction. J Neural Transm. 2016. doi:10.1007/s00702-016-1559-9.

20. Schjetnan AGP, Faraji J, Metz GA, Tatsuno M, Luczak A. Transcranial direct current stimulation in stroke rehabilitation: a review of recent advancements. Stroke Res Treat. 2013;2013:1-14. doi:10.1155/2013/170256.

21. Benninger DH, Lomarev M, Lopez G, et al. Transcranial direct current stimulation for the treatment of Parkinson's disease. J Neurol Neurosurg Psychiatry. 2010;81(10):1105-11. doi:10.1136/jnnp.2009.202556.

22. Fritsch B, Reis J, Martinowich K, et al. Direct current stimulation promotes BDNF-dependent synaptic plasticity: potential implications for motor learning. Neuron. 2010;66(2):198-204. doi:10.1016/j.neuron.2010.03.035.

23. Kuo MF, Paulus W, Nitsche MA. Boosting focally-induced brain plasticity by dopamine. Cereb Cortex. 2008;18(3):648-51. doi:10.1093/cercor/bhm098.

24. Faria P, Hallett M, Miranda PC. A finite element analysis of the effect of electrode area and inter-electrode distance on the spatial distribution of the current density in tDCS. J Neural Eng. 2011;8(6):66017. doi:10.1088/1741-2560/8/6/066017.

25. Minhas P, Bikson M, Woods AJ, Alyssa R. Rosen A, Kessler SK. NIH Public Access. 2012. doi: 10.1109/ EMBC.2012.6346067.Transcranial.

26. Nitsche MA, Paulus W. Excitability changes induced in the human motor cortex by weak transcranial direct current stimulation. J Physiol. 2000;527(Pt 3):633-9.

27. Rroji O, Van Kuyck K, Nuttin B, Wenderoth N. Anodal tDCS over the primary motor cortex facilitates long-term memory formation reflecting use-dependent plasticity. PLoS ONE. 2015;10(5):e0127270. doi:10.1371/journal. pone.0127270.

28. Costa TL, Lapenta OM, Boggio PS, Ventura DF. Transcranial direct current stimulation as a tool in the study of sensory-perceptual processing. Atten Percept Psychophys. 2015;77(6):1813-40. doi:10.3758/s13414-015-0932-3.

29. Bastani A, Jaberzadeh S. A-tDCS differential modulation of corticospinal excitability: the effects of electrode size. Brain Stimul. 2013;6(6):932-7. doi:10.1016/j.brs.2013.04.005.

30. DaSilva AF, Volz MS, Bikson M, Fregni F. Electrode positioning and montage in transcranial direct current stimulation. J Vis Exp. 2011;51:e2744. doi:10.3791/2744.

31. Lindenberg R, Renga V, Zhu LL, Nair D, Schlaug G. Bihemispheric brain stimulation facilitates motor recovery in chronic stroke patients. Neurology. 2010;75(24):2176-84. doi:10.1212/WNL.0b013e318202013a.

32. Kwon $\mathrm{YH}$, Ko M-H, Ahn SH, et al. Primary motor cortex activation by transcranial direct current stimulation in the human brain. Neurosci Lett. 2008;435(1):56-9. doi:10.1016/j.neulet.2008.02.012.

33. Schneider HD, Hopp JP. The use of the Bilingual Aphasia Test for assessment and transcranial direct current stimulation to modulate language acquisition in minimally verbal children with autism. Clin Linguist Phon. 2011;25:640-54. doi:10.3109/02699206.2011.570852.

34. Ardolino G, Bossi B, Barbieri S, Priori A. Non-synaptic mechanisms underlie the after-effects of cathodal transcutaneous direct current stimulation of the human brain. J Physiol. 2005;568(Pt 2):653-63. doi:10.1113/ jphysiol.2005.088310.

35. Lefaucheur JP. Principles of therapeutic use of transcranial and epidural cortical stimulation. Clin Neurophysiol. 2008;119(10):2179-84. doi:10.1016/j.clinph.2008.07.007.

36. Boggio PS, Zaghi S, Lopes M, Fregni F. Modulatory effects of anodal transcranial direct current stimulation on perception and pain thresholds in healthy volunteers. Eur J Neurol. 2008;15(10):1124-30. doi:10.1111/j.1468-1331.2008.02270.x.

37. Boggio PS, Zaghi S, Fregni F. Modulation of emotions associated with images of human pain using anodal transcranial direct current stimulation (tDCS). Neuropsychologia. 2009;47(1):212-7. doi:10.1016/j. neuropsychologia.2008.07.022

38. Chiken S, Nambu A. Mechanism of deep brain stimulation: inhibition, excitation, or disruption? Neuroscientist. 2015. doi:10.1177/1073858415581986.

39. Rossi S, Hallett M, Rossini PM, Pascual-Leone A. Safety, ethical considerations, and application guidelines for the use of transcranial magnetic stimulation in clinical practice and research. Clin Neurophysiol. 2009;120(12):2008-39. doi:10.1016/j.clinph.2009.08.016.

40. Tanaka S, Watanabe K. Transcranial direct current stimulation - a new tool for human cognitive neuroscience. Brain Nerve Shinkei kenkyu no shinpo. 2009;61(1):53-64.

41. Gandiga PC, Hummel FC, Cohen LG. Transcranial DC stimulation (tDCS): a tool for double-blind sham-controlled clinical studies in brain stimulation. Clin Neurophysiol. 2006;117(4):845-50. doi:10.1016/j.clinph.2005.12.003.

42. Cabral ME, Baltar A, Borba R, et al. Transcranial direct current stimulation: before, during, or after motor training? NeuroReport. 2015;26(11):618-22. doi:10.1097/WNR.0000000000000397.

43. Salvador R, Wenger C, Miranda PC. Investigating the cortical regions involved in MEP modulation in tDCS. Front Cell Neurosci. 2015;9:405. doi:10.3389/fncel.2015.00405. 
44. Nitsche MA, Paulus W. Sustained excitability elevations induced by transcranial DC motor cortex stimulation in humans. Neurology. 2001;57(10):1899-901. doi:10.1212/WNL.57.10.1899.

45. Rango M, Cogiamanian F, Marceglia S, et al. Myoinositol content in the human brain is modified by transcranial direct current stimulation in a matter of minutes: a 1H-MRS study. Magn Reson Med. 2008;60(4):782-9. doi:10.1002/mrm.21709.

46. Merzagora AC, Foffani G, Panyavin I, et al. Prefrontal hemodynamic changes produced by anodal direct current stimulation. Neuroimage. 2010;49(3):2304-10. doi:10.1016/j.neuroimage.2009.10.044.

47. Takai $\mathrm{H}$, Tsubaki A, Sugawara K, et al. Effect of transcranial direct current stimulation over the primary motor cortex on cerebral blood flow: a time course study using near-infrared spectroscopy. Adv Exp Med Biol. 2016;876:335-41. doi:10.1007/978-1-4939-3023-4_42.

48. Molaee-Ardekani B, Márquez-Ruiz J, Merlet I, et al. Effects of transcranial direct current stimulation (tDCS) on cortical activity: a computational modeling study. Brain Stimul. 2012;6(1):1-15. doi:10.1016/j.brs.2011.12.006.

49. Liebetanz D, Nitsche MA, Tergau F, Paulus W. Pharmacological approach to the mechanisms of transcranial DC stimulation induced after effects of human motor cortex excitability. Brain. 2002;125(10):2238-47. doi:10.1093/ brain/awf238.

50. Stagg CJ, Best JG, Stephenson MC, et al. Polarity-sensitive modulation of cortical neurotransmitters by transcranial stimulation. J Neurosci. 2009;29(16):5202-6. doi:10.1523/JNEUROSCI.4432-08.2009.

51. Nitsche MA, Kuo MF, Karrasch R, Wächter B, Liebetanz D, Paulus W. Serotonin affects transcranial direct currentinduced neuroplasticity in humans. Biol Psychiatry. 2009;66(5):503-8. doi:10.1016/j.biopsych.2009.03.022.

52. Izumi Y, Zorumski CF. Direct cortical inputs erase long-term potentiation at Schaffer collateral synapses. J Neurosci. 2008;28(38):9557-63. doi:10.1523/JNEUROSCI.3346-08.2008.

53. Márquez-Ruiz J, Leal-Campanario R, Sánchez-Campusano R, et al. Transcranial direct-current stimulation modulates synaptic mechanisms involved in associative learning in behaving rabbits. Proc Natl Acad Sci USA. 2012;109(17):6710-5. doi:10.1073/pnas.1121147109.

54. Nitsche MA, Grundey J, Liebetanz D, Lang N, Tergau F, Paulus W. Catecholaminergic consolidation of motor cortical neuroplasticity in humans. Cereb Cortex. 2004;14(11):1240-5. doi:10.1093/cercor/bhh085.

55. Clarkson AN, Huang BS, Macisaac SE, Mody I, Carmichael ST. Reducing excessive GABA-mediated tonic inhibition promotes functional recovery after stroke. Nature. 2010;468(7321):305-9. doi:10.1038/nature09511.

56. Filho PRM, Vercelino R, Cioato SG, et al. Transcranial direct current stimulation (tDCS) reverts behavioral alterations and brainstem BDNF level increase induced by neuropathic pain model: long-lasting effect. Prog Neuro-Psychopharmacol Biol Psychiatry. 2016;64:44-51. doi:10.1016/j.pnpbp.2015.06.016.

57. Iyer MB, Mattu U, Grafman J, Lomarev M, Sato S, Wassermann EM. Safety and cognitive effect of frontal DC brain polarization in healthy individuals. Neurology. 2005;64(5):872-5. doi:10.1212/01.WNL.0000152986.07469.E9.

58. Minhas P, Datta A, Bikson M. Cutaneous perception during tDCS: role of electrode shape and sponge salinity. Clin Neurophysiol. 2011;122(4):637-8. doi:10.1016/j.clinph.2010.09.023.

59. Vandermeeren Y, Jamart J, Ossemann M. Effect of tDCS with an extracephalic reference electrode on cardio-respiratory and autonomic functions. BMC Neurosci. 2010;11:38. doi:10.1186/1471-2202-11-38.

60. Poreisz C, Boros K, Antal A, Paulus W. Safety aspects of transcranial direct current stimulation concerning healthy subjects and patients. Brain Res Bull. 2007;72(4-6):208-14. doi:10.1016/j.brainresbull.2007.01.004.

61. Palm U, Keeser D, Schiller C, et al. Skin lesions after treatment with transcranial direct current stimulation (tDCS). Brain Stimul. 2008;1 (4):386-7. doi:10.1016/j.brs.2008.04.003.

62. Bikson M, Datta A, Elwassif M. Establishing safety limits for transcranial direct current stimulation. Clin Neurophysiol. 2009;120(6):1033-4. doi:10.1016/j.clinph.2009.03.018.

63. Bikson M, Grossman P, Thomas C, et al. Safety of transcranial direct current stimulation: evidence based update 2016. Brain Stimul. 2016. doi:10.1016/j.brs.2016.06.004.

64. van Asseldonk EHF, Boonstra TA. Transcranial direct current stimulation of the leg motor cortex enhances coordinated motor output during walking with a large inter-individual variability. Brain Stimul. 2016;9(2):182-90 doi:10.1016/j.brs.2015.10.001.

65. Galea JM, Jayaram G, Ajagbe L, Celnik P. Modulation of cerebellar excitability by polarity-specific noninvasive direct current stimulation. J Neurosci. 2009;29(28):9115-22. doi:10.1523/JNEUROSCI.2184-09.2009.

66. Jayaram G, Tang B, Pallegadda R, Vasudevan EVL, Celnik P, Bastian A. Modulating locomotor adaptation with cerebellar stimulation. J Neurophysiol. 2012;107(11):2950-7. doi:10.1152/jn.00645.2011.

67. Kim CR, Kim D-Y, Kim LS, Chun MH, Kim SJ, Park CH. Modulation of cortical activity after anodal transcranial direct current stimulation of the lower limb motor cortex: a functional MRI study. Brain Stimul. 2012;5(4):462-7. doi:10.1016/j.brs.2011.08.002.

68. Madhavan S, Stinear JW. Focal and bidirectional modulation of lower limb motor cortex using anodal transcranial direct current stimulation. Brain Stimul. 2010;3(1):42-50. doi:10.1016/j.brs.2009.06.005.

69. Jeffery DT, Norton JA, Roy FD, Gorassini MA. Effects of transcranial direct current stimulation on the excitability of the leg motor cortex. Exp Brain Res. 2007;182:281-87. doi:10.1007/s00221-007-1093-y.

70. Reis J, Fritsch B. Modulation of motor performance and motor learning by transcranial direct current stimulation. Curr Opin Neurol. 2011;24(6):590-6. doi:10.1097/WCO.0b013e32834c3db0.

71. Hashemirad F, Zoghi M, Fitzgerald PB, Jaberzadeh S. The effect of anodal transcranial direct current stimulation on motor sequence learning in healthy individuals: a systematic review and meta-analysis. Brain Cogn. 2016;102:112. doi:10.1016/j.bandc.2015.11.005.

72. Kwon YH, Kwon JW. Response inhibition induced in the stop-signal task by transcranial direct current stimulation of the pre-supplementary motor area and primary sensoriomotor cortex. J Phys Ther Sci. 2013;25(9):1083-6. doi:10.1589/jpts.25.1083.

73. Agata FD, Peila E, Cicerale A, et al. Cognitive and neurophysiological effects of non-invasive brain stimulation in stroke patients after motor rehabilitation. Front Behav Neurosci. 2016;10:1-11. doi:10.3389/fnbeh.2016.00135.

74. Schlaug G, Renga V, Nair D. Transcranial direct current stimulation in stroke recovery. Stroke. 2009;65(12):1571-6. doi:10.1001/archneur.65.12.1571.Transcranial. 
75. Nair DG, Renga V, Lindenberg R, et al. Optimizing recovery potential through simultaneous occupational therapy and non-invasive brain-stimulation using tDCS. Restor Neurol Neurosci. 2015;29(6):411-20. doi:10.3233/RNN-20110612.Optimizing.

76. O'Shea J, Boudrias M, Jane C, et al. Neurolmage predicting behavioural response to TDCS in chronic motor stroke. Neuroimage. 2014;85:924-33. doi:10.1016/j.neuroimage.2013.05.096.

77. Hummel F, Celnik P, Giraux P, et al. Effects of non-invasive cortical stimulation on skilled motor function in chronic stroke. Brain. 2005;128(3):490-9. doi:10.1093/brain/awh369.

78. Rosso C, Perlbarg V, Valabregue R, et al. Broca's area damage is necessary but not sufficient to induce aftereffects of cathodal tDCS on the unaffected hemisphere in post-stroke aphasia. Brain Stimul. 2014;7(5):627-35. doi:10.1016/j.brs.2014.06.004.

79. Málly J. Non-invasive brain stimulation (rTMS and tDCS) in patients with aphasia: mode of action at the cellular level. Brain Res Bull. 2013;98:30-5. doi:10.1016/j.brainresbull.2013.07.005.

80. Gordon C, Hewer RL, Wade DT. Dysphagia in acute stroke. Br Med J (Clin Res Ed). 1987;295(6595):411-4. doi:10.1136/bmj.295.6606.1137-c.

81. Barer DH. The natural history and functional consequences of dysphagia after hemispheric stroke. J Neurol Neurosurg Psychiatry. 1989;52(2):236-41. doi:10.1136/jnnp.52.2.236.

82. Martin RE, Sessle BJ. The role of the cerebral cortex in swallowing. Dysphagia. 1993;8(3):195-202. doi:10.1007/ BF01354538.

83. Hamdy S, Rothwell JC, Aziz Q, Thompson DG. Organization and reorganization of human swallowing motor cortex: implications for recovery after stroke. Clin Sci. 2000;99(2):151-7. doi:10.1042/CS19990300.

84. Sandrini M, Cohen LG. Noninvasive brain stimulation in neurorehabilitation. Handb Clin Neurol. 2013;116:499-524. doi:10.1016/B978-0-444-53497-2.00040-1.

85. Kumar S, Wagner CW, Frayne C, et al. Noninvasive brain stimulation may improve stroke-related dysphagia: a pilot study. Stroke. 2011;42(4):1035-40. doi:10.1161/STROKEAHA.110.602128.

86. Yang EJ, Baek S-R, Shin J, et al. Effects of transcranial direct current stimulation (tDCS) on post-stroke dysphagia. Restor Neurol Neurosci. 2012;30(4):303-11. doi:10.3233/RNN-2012-110213.

87. Hickey P, Stacy M. Deep brain stimulation: a paradigm shifting approach to treat Parkinson's disease. Front Neurosci. 2016;10:1-11. doi:10.3389/fnins.2016.00173.

88. Broeder S, Nackaerts E, Heremans E, et al. Transcranial direct current stimulation in Parkinson's disease: neurophysiological mechanisms and behavioral effects. Neurosci Biobehav Rev. 2015;57:105-17. doi:10.1016/j. neubiorev.2015.08.010.

89. Fregni F, Boggio PS, Santos MC, et al. Noninvasive cortical stimulation with transcranial direct current stimulation in Parkinson's disease. Mov Disord. 2006;21(10):1693-702. doi:10.1002/mds.21012.

90. Valentino F, Cosentino G, Brighina F, et al. Transcranial direct current stimulation for treatment of freezing of gait: a cross-over study. Mov Disord. 2014;29(8):1064-9. doi:10.1002/mds.25897.

91. Ferrucci R, Cortese F, Bianchi M, et al. Cerebellar and motor cortical transcranial stimulation decrease levodopainduced dyskinesias in Parkinson's disease. Cerebellum. 2016;15(1):43-7. doi:10.1007/s12311-015-0737-X.

92. Mehta S, Mclntyre A, Guy S, Teasell RW, Loh E. Effectiveness of transcranial direct current stimulation for the management of neuropathic pain after spinal cord injury: a meta-analysis. Spinal Cord. 2015;53:1-6. doi:10.1038/ sc.2015.118

93. Pérez-Fernández C, Sánchez-Kuhn A, Cánovas R, Flores P, Sánchez-Santed F. The effect of transcranial direct current stimulation (tDCS) over human motor function. 2016;9656. doi:10.1007/978-3-319-31744-1_43.

94. Cuypers K, Leenus DJF, Van Wijmeersch B, et al. Anodal tDCS increases corticospinal output and projection strength in multiple sclerosis. Neurosci Lett. 2013;554:151-5. doi:10.1016/j.neulet.2013.09.004.

95. Meesen RLJ, Thijs H, Leenus DJF, Cuypers K. A single session of $1 \mathrm{~mA}$ anodal tDCS-supported motor training does not improve motor performance in patients with multiple sclerosis. Restor Neurol Neurosci. 2013. doi:10.3233/ RNN-130348.

96. Mori F, Nicoletti CG, Kusayanagi H, et al. Transcranial direct current stimulation ameliorates tactile sensory deficit in multiple sclerosis. Brain Stimul. 2013;6(4):654-9. doi:10.1016/j.brs.2012.10.003.

97. Mori F, Codecà C, Kusayanagi $\mathrm{H}$, et al. Effects of anodal transcranial direct current stimulation on chronic neuropathic pain in patients with multiple sclerosis. J Pain. 2010;11(5):436-42. doi:10.1016/j.jpain.2009.08.011.

98. Di Lazzaro V, Ranieri F, Capone F, Musumeci G, Dileone M. Direct current motor cortex stimulation for amyotrophic lateral sclerosis: a proof of principle study. Brain Stimul. 2013;6(6):969-70. doi:10.1016/j.brs.2013.06.005.

99. Munneke MAM, Stegeman DF, Hengeveld YA, Rongen JJ, Jurgen Schelhaas H, Zwarts MJ. Transcranial direct current stimulation does not modulate motor cortex excitability in patients with Amyotrophic lateral sclerosis. Muscle Nerve. 2011; 44(1):109-114. http://www.scopus.com/inward/record.url?eid=2-s2.0-79959303196\&partnerl $\mathrm{D}=40 \& \mathrm{md5}=4 \mathrm{~d} 95 \mathrm{bca} 297 \mathrm{~b} 6 \mathrm{a} 129 \mathrm{add} 535 \mathrm{~b} 0786 \mathrm{c} 6 \mathrm{eaa}$.

100. Quartarone A, Lang N, Rizzo V, et al. Motor cortex abnormalities in amyotrophic lateral sclerosis with transcranial direct-current stimulation. Muscle Nerve. 2007;35(5):620-4. doi:10.1002/mus.20737.

101. Munneke MAM, Rongen JJ, Overeem S, Schelhaas HJ, Zwarts MJ, Stegeman DF. Cumulative effect of 5 daily sessions of $\theta$ burst stimulation on corticospinal excitability in amyotrophic lateral sclerosis. Muscle Nerve. 2013:48(5):733-8. doi:10.1002/mus.23818.

102. Silva FTG, Raulino JTP, Reynaud FR, et al. Transcranial direct current stimulation on the autonomic modulation and exercise time in individuals with spinal cord injury. A case report. Auton Neurosci Basic Clin. 2015; 193:152-5. http://www.elsevier.com/locate/jans\%5Cnhttp://ovidsp.ovid.com/ovidweb.cgi?T=JS\&PAGE=reference\&D=emed $13 \& N E W S=N \& A N=2015335706$

103. Murray LM, Edwards DJ, Ruffini G, et al. Intensity dependent effects of transcranial direct current stimulation on corticospinal excitability in chronic spinal cord injury. Arch Phys Med Rehabil. 2014;96(4 Suppl):S114-21. doi:10.1016/j.apmr.2014.11.004 (Epub 2014 Nov 22) 
104. Hubli M, Dietz V, Schraf-Altermatt M, Bolliger M. Modulation of spinal neuronal excitability by spinal direct currents and locomotion after spinal cord injury. Clin Neurophysiol. 2013;124(6):1187-95. doi:10.1016/j. clinph.2012.11.021.

105. Cogiamanian F, Vergari M, Pulecchi F, Marceglia S, Priori A. Effect of spinal transcutaneous direct current stimulation on somatosensory evoked potentials in humans. Clin Neurophysiol. 2008;1 19(11):2636-40. doi:10.1016/j. clinph.2008.07.249.

106. Barrière G, Cazalets JR, Bioulac B, Tison F, Ghorayeb I. The restless legs syndrome. Prog Neurobiol. 2005;77(3):13965. doi:10.1016/j.pneurobio.2005.10.007.

107. Heide AC, Winkler T, Helms HJ, et al. Effects of transcutaneous spinal direct current stimulation in idiopathic restless legs patients. Brain Stimul. 2014;7(5):636-42. doi:10.1016/j.brs.2014.06.008.

108. Koo Yong Seo, Kim SM, et al. Transcranial direct current stimulation on primary sensorimotor area has no effect in patients with drug-naive restless legs syndrome: a proof-of-concept clinical trial. Sleep Med. 2015;16(2):280-7. doi:10.1016/j.sleep.2014.07.032.

109. De Almeida JR, Guyatt GH, Sud S, et al. Management of Bell palsy: clinical practice guideline. CMAJ. 2014;186(12):917-22. doi:10.1503/cmaj.131801.

110. Minhas P, Bikson M, Woods AJ, Rosen AR, Kessler SK. Transcranial direct current stimulation in pediatric brain: a computational modeling study. Conf Proc IEEE Eng Med Biol Soc. 2012;2012:859-62. doi:10.1109/ EMBC.2012.6346067.

111. Duarte NDAC, Grecco LAC, Galli M, Fregni F, Oliveira CS. Effect of transcranial direct-current stimulation combined with treadmill training on balance and functional performance in children with cerebral palsy: a double-blind randomized controlled trial. PLoS ONE. 2014;9(8):e105777. doi:10.1371/journal.pone.0105777.

112. Kheder A, Nair KPS. Spasticity: pathophysiology, evaluation and management. Pract Neurol. 2012;12(5):289-98. doi:10.1136/practneurol-2011-000155.

113. Aree-Uea B, Auvichayapat N, Janyacharoen T, et al. Reduction of spasticity in cerebral palsy by anodal transcranial direct current stimulation. J Med Assoc Thail. 2014;97(9):954-62.

114. Delasta Lazzari R, Politti F, Almeida Santos C, et al. Effect of a single session of transcranial direct-current stimulation combined with virtual reality training on the balance of children with cerebral palsy: a randomized, controlled, double-blind trial. J Phys Ther Sci. 2015;27:763-8.

115. André L, Grecco C, De N, et al. Effects of anodal transcranial direct current stimulation combined with virtual reality for improving gait in children with spastic diparetic cerebral palsy: a pilot, randomized, controlled, doubleblind, clinical trial. Clin Rehabil. 2015. doi:10.1177/0269215514566997.

116. Teo W, Muthalib M, Yamin S, Hendy AM, Bramstedt K, Reilly RB. Does a combination of virtual reality, neuromodulation and neuroimaging provide a comprehensive platform for neurorehabilitation ?-A narrative review of the literature. Front Hum Neurosci. 2016;10:1-15. doi:10.3389/fnhum.2016.00284.

117. Parkin BL, Ekhtiari H, Walsh VF. Non-invasive human brain stimulation in cognitive neuroscience: a primer. Neuron. 2015;87(5):932-45. doi:10.1016/j.neuron.2015.07.032.

118. Woods AJ, Antal A, Bikson M, et al. A technical guide to tDCS, and related non-invasive brain stimulation tools. Clin Neurophysiol. 2016;127(2):1031-48. doi:10.1016/j.clinph.2015.11.012.

119. Wiethoff $S$, Hamada M, Rothwell JC. Variability in response to transcranial direct current stimulation of the motor cortex. Brain Stimul. 2014;7(3):468-75. doi:10.1016/j.brs.2014.02.003.

120. Schlaug G. Musicians and music making as a model for the study of brain plasticity. Prog Brain Res. 2015;217:3755. doi:10.1016/bs.pbr.2014.11.020

121. Saucedo Marquez CM, Zhang X, Swinnen SP, Meesen R, Wenderoth N. Task-specific effect of transcranial direct current stimulation on motor learning. Front Hum Neurosci. 2013;7(July):333. doi:10.3389/fnhum.2013.00333.

122. Furuya S, Klaus M, Nitsche MA, Paulus W, Altenmüller E. Ceiling effects prevent further improvement of transcranial stimulation in skilled musicians. J Neurosci. 2014. doi:10.1523/JNEUROSCI.1170-14.2014.

123. Krings $\mathrm{T}$, Töpper R, Foltys $\mathrm{H}$, et al. Cortical activation patterns during complex motor tasks in piano players and control subjects. A functional magnetic resonance imaging study. Neurosci Lett. 2000;278(3):189-93. doi:10.1016/ S0304-3940(99)00930-1.

124. Wright DJ, Holmes PS, Di Russo F, Loporto M, Smith D. Differences in cortical activity related to motor planning between experienced guitarists and non-musicians during guitar playing. Hum Mov Sci. 2012;31(3):567-77. doi:10.1016/j.humov.2011.07.001.

125. Koeneke S, Lutz K, Wüstenberg T, Jäncke L. Long-term training affects cerebellar processing in skilled keyboard players. NeuroReport. 2004;15(8):1279-82. doi:10.1097/01.wnr.0000127463.10147.

126. Hasan A, Misewitsch K, Nitsche MA, et al. Impaired motor cortex responses in non-psychotic first-degree relatives of schizophrenia patients: a cathodal tDCS pilot study. Brain Stimul. 2013;6(5):821-9. doi:10.1016/j.brs.2013.03.001.

127. Lang N, Siebner HR, Ward NS, et al. How does transcranial DC stimulation of the primary motor cortex alter regional neuronal activity in the human brain? Eur J Neurosci. 2005;22(2):495-504. doi:10.1111/j.1460-9568.2005.04233.x.

128. Kuo H, Bikson M, Datta A, et al. Brain stimulation comparing cortical plasticity induced by conventional and highdefinition 4 Â 1 ring tDCS: a neurophysiological study. Brain Stimul. 2013;6(4):644-8. doi:10.1016/j.brs.2012.09.010

129. Datta A, Elwassif M, Bikson M. Bio-heat transfer model of transcranial DC stimulation: Comparison of conventional pad versus ring electrode. In: Proceedings of the 31st annual international conference of the IEEE engineering in medicine and biology society: engineering the future of biomedicine, EMBC 2009. 2009; 670-3. doi: 10.1109/ IEMBS.2009.5333673.

130. Roy A, Baxter B, He B. High-definition transcranial direct current stimulation induces both acute and persistent changes in broadband cortical synchronization: a simultaneous tDCS-EEG study. IEEE Trans Biomed Eng. 2014;61(7):1967-78. doi:10.1109/TBME.2014.2311071.

131. Garnett EO, den Ouden D-B. Validating a sham condition for use in high definition transcranial direct current stimulation. Brain Stimul. 2015;8(3):551-4. doi:10.1016/..brs.2015.01.399. 
132. Been G, Ngo TT, Miller SM, Fitzgerald PB. The use of tDCS and CVS as methods of non-invasive brain stimulation. Brain Res Rev. 2007;56(2):346-61. doi:10.1016/j.brainresrev.2007.08.001.

133. Brunoni AR, Nitsche MA, Bolognini N, et al. Clinical research with transcranial direct current stimulation (tDCS): challenges and future directions. Brain Stimul. 2012;5(3):175-95. doi:10.1016/j.brs.2011.03.002.

134. Radman T, Ramos RL, Brumberg JC, Bikson M. Role of cortical cell type and morphology in subthreshold and suprathreshold uniform electric field stimulation in vitro. Brain Stimul. 2009;2(4):215-28. doi:10.1016/j. brs.2009.03.007.

135. Brunoni AR, Ferrucci R, Bortolomasi M, et al. Interactions between transcranial direct current stimulation (tDCS) and pharmacological interventions in the Major Depressive Episode: findings from a naturalistic study. Eur Psychiatry. 2013;28(6):356-61. doi:10.1016/j.eurpsy.2012.09.001.

136. Kouzani AZ, Jaberzadeh S, Zoghi M, Usma C, Parastarfeizabadi M. Development and validation of a miniature programmable tDCS device. IEEE Trans Neural Syst Rehabil Eng. 2016;24(1):192-8. doi:10.1109/TNSRE.2015.2468579.

Submit your next manuscript to BioMed Central and we will help you at every step:

- We accept pre-submission inquiries

- Our selector tool helps you to find the most relevant journal

- We provide round the clock customer support

- Convenient online submission

- Thorough peer review

- Inclusion in PubMed and all major indexing services

- Maximum visibility for your research

Submit your manuscript at www.biomedcentral.com/submit 